\title{
Lung Function Impairment and the Risk of Incident Dementia: The Rotterdam Study
}

\author{
Tian Xiao ${ }^{\mathrm{a}, 1}$, Sara R.A. Wijnant ${ }^{\mathrm{a}, \mathrm{b}, \mathrm{c}, 1}$, Silvan Licher ${ }^{\mathrm{a}}$, Natalie Terzikhan ${ }^{\mathrm{a}}$, Lies Lahousse ${ }^{\mathrm{c}}$, \\ M. Kamran Ikram ${ }^{\mathrm{a}, \mathrm{d}}$, Guy G. Brusselle $\mathrm{a}^{\mathrm{a}, \mathrm{b}, \mathrm{e}, *}$ and M. Arfan Ikram ${ }^{\mathrm{a}, *}$ \\ ${ }^{a}$ Department of Epidemiology, Erasmus Medical Center, Rotterdam, The Netherlands \\ ${ }^{\mathrm{b}}$ Department of Respiratory Medicine, Ghent University Hospital, Ghent, Belgium \\ ${ }^{\mathrm{c}}$ Department of Bioanalysis, Faculty of Pharmaceutical Sciences, Ghent University, Ghent, Belgium \\ ${ }^{\mathrm{d}}$ Department of Neurology, Erasmus Medical Center, Rotterdam, The Netherlands \\ ${ }^{\mathrm{e}}$ Department of Respiratory Medicine, Erasmus Medical Center, Rotterdam, The Netherlands
}

Accepted 26 April 2021

Pre-press 28 May 2021

\begin{abstract}
.
Background: The etiology of dementia may partly be underpinned by impaired lung function via systemic inflammation and hypoxia.

Objective: To prospectively examine the association between chronic obstructive pulmonary disease (COPD) and subclinical impairments in lung function and the risk of dementia.

Methods: In the Rotterdam Study, we assessed the risk of incident dementia in participants with Preserved Ratio Impaired Spirometry (PRISm; $\mathrm{FEV}_{1} / \mathrm{FVC} \geq 0.7, \mathrm{FEV}_{1}<80 \%$ predicted) and in participants with $\mathrm{COPD}\left(\mathrm{FEV}_{1} / \mathrm{FVC}<0.7\right)$ compared to those with normal spirometry (controls; $\mathrm{FEV}_{1} / \mathrm{FVC} \geq 0.7, \mathrm{FEV}_{1} \geq 80 \%$ predicted). Hazard ratios (HRs) with $95 \%$ confidence intervals $(\mathrm{CI})$ for dementia were adjusted for age, sex, education attainment, smoking status, systolic blood pressure, body mass index, triglycerides, comorbidities and Apolipoprotein $\mathrm{E}$ (APOE) genotype.

Results: Of 4,765 participants, 110 (2.3\%) developed dementia after 3.3 years. Compared to controls, participants with PRISm, but not COPD, had an increased risk for all-type dementia (adjusted $\mathrm{HR}_{\mathrm{PRISm}}$ 2.70; 95\% CI, 1.53-4.75; adjusted $\left.\mathrm{HR}_{\mathrm{COPD}} 1.03 ; 95 \% \mathrm{CI}, 0.61-1.74\right)$. These findings were primarily driven by men and smokers. Similarly, participants with FVC\% predicted values in the lowest quartile compared to those in the highest quartile were at increased risk of all-type dementia (adjusted HR 2.28; 95\% CI, 1.31-3.98), as well as Alzheimer's disease (AD; adjusted HR 2.13; 95\% CI, 1.13-4.02). Conclusion: Participants with PRISm or a low FVC\% predicted lung function were at increased risk of dementia, compared to those with normal spirometry or a higher FVC\% predicted, respectively. Further research is needed to elucidate whether this association is causal and how PRISm might contribute to dementia pathogenesis.
\end{abstract}

Keywords: Alzheimer's disease, chronic obstructive pulmonary disease, dementia, forced vital capacity (FVC), preserved ratio impaired spirometry

\footnotetext{
${ }^{1}$ These authors contributed equally to this work.

*Correspondence to: Guy G. Brusselle, PhD, Department of Respiratory Medicine, University Hospital Ghent, Corneel Heymanslaan 10, 9000 Ghent, Belgium. E-mail: guy.brusselle@ ugent.be and M. Arfan Ikram, PhD, Department of Epidemiology, Erasmus Medical Center, Rotterdam, The Netherlands. E-mail: m.a.ikram@erasmusmc.nl.
}

\section{INTRODUCTION}

Dementia is characterized by poor cognitive performance interfering with activities of daily living and impaired health-related quality of life at older ages [1], with an increasing prevalence worldwide [2]. In order to mitigate the burden of dementia through postponement or prevention, and to respond adequately on such a major health problem, the 
identification of key modifiable risk factors is warranted and include smoking, obesity, hypertension, depression, sleep apnea, diabetes, and hyperlipidemia [3]. Chronic obstructive pulmonary disease (COPD) and decreased lung volume capacity have also been associated with a greater risk of dementia and compromised cognitive ability [4]. Possible etiological links with dementia comprise systemic inflammation and hypoxia induced oxidative stress [4-6].

More recently, preserved ratio impaired spirometry (PRISm) — with a prevalence ranging from 3\% to $20 \%$ in adults [7] — has emerged as a clinically relevant entity related to premature mortality $[7,8]$, but thus far has been largely understudied, because of a hitherto stronger focus on COPD. The term PRISm encompasses the findings of restrictive respiratory pattern with impaired spirometry, i.e., decreased forced expiratory volume in one second $\left(\mathrm{FEV}_{1}\right)$ or forced vital capacity (FVC) but preserved $\mathrm{FEV}_{1} / \mathrm{FVC}$ ratio [7]. People with PRISm suffer from lung function restriction but due to normal range of $\mathrm{FEV}_{1} / \mathrm{FVC}$ ratio would not be diagnosed as COPD according to the GOLD guidelines in clinical practice [7, 9]. Previous studies have suggested PRISm is a fluctuating state, serving as an intermediate phase between normal spirometry and COPD $[8,10]$. However, very little is known about the clinical sequelae of PRISm, including risk of dementia.

Therefore, the aim of this study was to investigate the association of both COPD and subclinical reduced lung function, as evidenced by the presence of impaired lung volumes (PRISm), with the risk of dementia at follow-up within a prospective population-based cohort study.

\section{METHODS}

This study was conducted within the Rotterdam Study, a prospective cohort study that started in 1990, comprising almost 15,000 participants aged at least 45 years, with the aim of studying chronic diseases in the general population [11]. Every four to five years, participants underwent follow-up examinations, consisting of a home interview and various physical examinations at the research center. We used data collected between 2009 and 2014 as baseline for this study, when participants underwent spirometry at the research center. A total of 4,765 persons with interpretable spirometry and without asthma and without prevalent dementia were retained for analyses (Fig. 1).

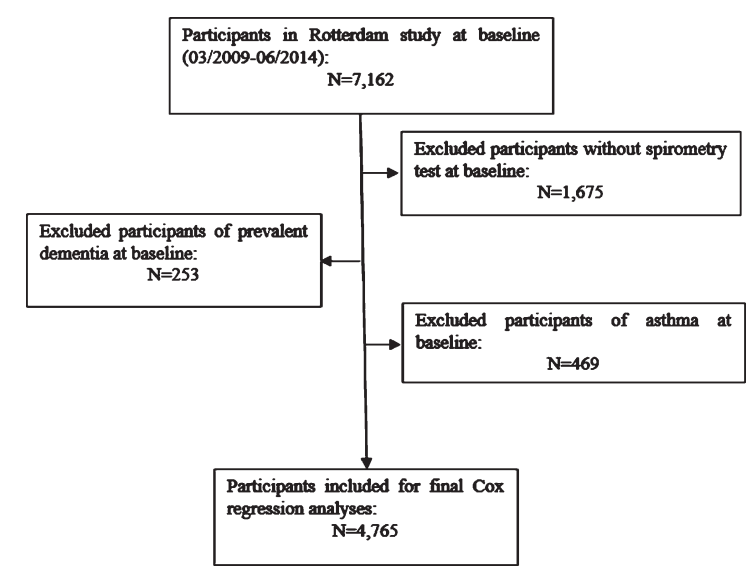

Fig. 1. Flow chart for participants with interpretable spirometry at baseline, informed consent for follow-up and graph for definition of lung function categories.

\section{Standard protocol approvals, registrations, and patients consents}

The study had been approved by the medical ethics committee of the Erasmus Medical Centre (Rotterdam, the Netherlands), and the review board of the Netherlands Ministry of Health, Welfare and Sports (1068889-159521-PG). Informed consent was provided by all participants.

\section{Spirometry test}

Lung function was assessed via pre-bronchodilator spirometry performed by trained paramedical personnel using a Master Screen PFT Pro (Care Fusion, Netherlands) according to the American Thoracic Society (ATS)/European Respiratory Society (ERS) guidelines [12]. Predicted FVC and predicted FEV 1 values were calculated using Global Lung Initiative (GLI) reference equations taking age, sex, height, and ethnicity into account [13]. Based on these values, the following subgroups were defined: COPD $\left(\mathrm{FEV}_{1} / \mathrm{FVC}<70 \%\right), \mathrm{PRISm}\left(\mathrm{FEV}_{1} / \mathrm{FVC} \geq 70 \%\right.$ and $\mathrm{FEV}_{1}<80 \%$ predicted), and normal spirometry $\left(\mathrm{FEV}_{1} / \mathrm{FVC} \geq 70 \%\right.$ and an $\mathrm{FEV}_{1} \geq 80 \%$ predicted $)$ were distinguished [7,9]. Spirometry was conducted in accordance with the ATS/ERS guidelines [12, 13], with specific preparatory instructions, e.g., with respect to smoking or other factors. In order to guarantee the reliability and reproducibility, at least two spirometry tests were implemented on each participant, and the best reading was obtained. No specific preparatory instructions were given (e.g., related to smoking or other factors). The quartile categories of 
lung function parameters were derived from values in this study, which is similar to quintile subgroups in a previous study [14]. For calculation of trending hazard ratio with $10 \%$ change in lung function, lung function parameters were included in cox models after being divided by 10 . Airflow limitation was confirmed by the value of a post-bronchodilator $\mathrm{FEV}_{1} / \mathrm{FVC}$ below 0.7 [9].

\section{Dementia assessment}

Dementia assessment was conducted for participants at baseline and subsequent center visits with the Mini-Mental State Examination and the Geriatric Mental Schedule [15]. Those with a Mini-Mental State Examination score $<26$ or Geriatric Mental Schedule score $>0$ underwent further investigation along with an interview with a research physician, that contained the Cambridge Examination for Mental Disorders of the Elderly. The whole population also underwent routine cognitive assessment. Moreover, the entire cohort was continuously under surveillance for dementia through electronic linkage of the study database with medical records from general practitioners and the regional institute for outpatient mental health care. If available clinical neuroimaging was used for determining dementia subtype [11]. An adjudication panel led by a consultant neurologist established the final diagnosis according to standard criteria for dementia (Diagnostic and Statistical Manual of Mental Disorder, Third Edition-Revised: DSM-III-R) and AD (National Institute of Neurological and Communicative Disorders and Stroke-Alzheimer's Disease and Related Disorders Association: NINCDS-ADRDA). Follow-up until 14 December 2017 was virtually complete (95.5\% of potential person-years). Within this period, participants were followed until the date of dementia and $\mathrm{AD}$ diagnosis, death, loss to followup or 14 December 2017, whichever came first.

\section{Covariates}

The following variables were considered as possible confounders, primarily based on previous literature and their role as shared causes between lung function and dementia. Demographic information included age, sex, education level (primary education, lower education, intermediate education, higher education), smoking status (never, former, current), systolic blood pressure $(\mathrm{mmHg})$, body mass index (BMI, $\mathrm{kg} / \mathrm{m}^{2}$, calculated by weight $[\mathrm{kg}]$ divided by height [m] squared), and chronic comorbid conditions (diabetes and stroke) [11]. Blood samples were extracted for determination of levels of triglycerides and DNA at the research center. Apolipoprotein E (APOE) genotype was determined using a PCR in the original cohort (RS-I, starting between July 1989 and September 1993) and a bi-allelic TaqMan assay (rs7412 and rs429358) on labeled DNA samples in the two cohorts (RS-II-3, starting between February 2000 and December 2001; and RS-III-2, starting between February 2006 and December 2008), respectively. This study included these three sub-cohorts. $A P O E \varepsilon 4$ represented carrier of one or two $\varepsilon 4$ alleles. Participants were categorized into three groups: high genetic risk ( $\varepsilon 2 / \varepsilon 4, \varepsilon 3 / \varepsilon 4$, or $\varepsilon 4 / \varepsilon 4$ genotypes), intermediate risk $(\varepsilon 3 / \varepsilon 3)$, or low risk $(\varepsilon 2 / \varepsilon 2$ or $\varepsilon 2 / \varepsilon 3)$ [16]. As the strongest genetic risk factor for dementia, $A P O E$ has additionally potent cardiovascular effects, including arteriosclerosis and cardiac function. In this regard, $A P O E$ may also impact lung function. We therefore included $A P O E$ in the models as possible confounder $[14,17]$. Missing values were handled by five-times imputation using chained equation [18].

\section{Statistical analysis}

Baseline characteristics are described among subgroups of lung function. Data are expressed as mean \pm standard deviation (SD) for normally distributed variables or as median (interquartile range [IQR]) for non-normally distributed variables.

For analyses of the association between lung function at baseline and risk of incident dementia, we used Cox proportional-hazards regression analyses. Lung function was categorized as normal spirometry, PRISm, and COPD. In addition, lung volume capacity comprised subgroups of quartiles of $\mathrm{FEV}_{1} \%$ predicted, $\mathrm{FVC} \%$ predicted and ratio of $\mathrm{FEV}_{1} / \mathrm{FVC}$. Follow-up time started on the date of spirometry test at baseline and ended until diagnosis of dementia, death, lost to follow-up, or December 14, 2017. The proportional hazards assumption was checked using Schoenfeld residuals. Model 1 was adjusted for APOE category, age, sex, and education level. Model 2 was additionally adjusted for smoking status, BMI, systolic blood pressure, triglyceride, and comorbidity (history of stroke and diabetes mellitus). Covariates above were selected based on previous literature knowledge, clinical relevance and availability of the data. Given the relatively small number of incident cases of dementia, we also constructed a third model in which the covariates were accounted 
Table 1

Baseline characteristics of participants, stratified by lung function category

\begin{tabular}{|c|c|c|c|c|}
\hline & Normal & PRISm & COPD & $p$ \\
\hline$n(\%)$ & $3683(77.3)$ & $319(6.7)$ & $763(16.0)$ & - \\
\hline Age, y & $67.8(12.5)$ & $68.6(14.4)$ & $70.6(13.4)$ & $<0.001$ \\
\hline Female, $(\%)$ & $2120(57.6)$ & $171(53.6)$ & $324(42.5)$ & $<0.001$ \\
\hline \multicolumn{5}{|l|}{ Education level } \\
\hline Primary education & $246(6.8)$ & $31(9.9)$ & $81(10.7)$ & \multirow[t]{4}{*}{$<0.001$} \\
\hline lower education & $1445(39.7)$ & $117(37.1)$ & $279(36.9)$ & \\
\hline Intermediate education & $1089(29.8)$ & $93(29.5)$ & $249(32.9)$ & \\
\hline Higher education & $864(23.7)$ & $74(23.5)$ & $148(19.6)$ & \\
\hline \multicolumn{5}{|l|}{ Smoking status, $(\%)$} \\
\hline Never & $1383(37.6)$ & $97(30.4)$ & $135(17.7)$ & \multirow[t]{3}{*}{$<0.001$} \\
\hline Former & $1960(53.2)$ & $177(55.5)$ & $415(54.4)$ & \\
\hline Current & $340(9.2)$ & $45(14.1)$ & $213(27.9)$ & \\
\hline Systolic pressure & $141(29)$ & $142(29)$ & $142(26)$ & 0.369 \\
\hline Body mass index, $\mathrm{kg} / \mathrm{m} 2$ & $27.0(5.0)$ & $28.4(5.9)$ & $26.1(5.0)$ & $<0.001$ \\
\hline Triglycerides, mg/dl & $1.3(0.7)$ & $1.4(0.9)$ & $1.2(0.7)$ & $<0.001$ \\
\hline History of stroke & $34(0.9)$ & $7(2.2)$ & $12(1.6)$ & $0.040^{*}$ \\
\hline History of diabetes mellitus & $292(8.0)$ & $31(10.0)$ & $73(9.7)$ & 0.200 \\
\hline \multicolumn{5}{|c|}{ Apolipoprotein E genotype, $(\%)$} \\
\hline$\varepsilon 4$-allele positive & $937(27.3)$ & $66(22.8)$ & $196(27.8)$ & \multirow[t]{2}{*}{0.142} \\
\hline$\varepsilon 4$-allele negative & $2496(72.7)$ & $224(77.2)$ & $509(72.2)$ & \\
\hline $\mathrm{FEV}_{1} / \mathrm{FVC}$ & $78.7(6.4)$ & $76.1(7.1)$ & $65.6(7.6)$ & $<0.001$ \\
\hline $\mathrm{FEV}_{1} \%$ predicted & $103.2(18.7)$ & $73.8(10.6)$ & $79.1(24.7)$ & $<0.001$ \\
\hline FVC $\%$ predicted & $101.2(17.9)$ & $72.2(11.7)$ & $94.0(24.9)$ & $<0.001$ \\
\hline
\end{tabular}

COPD, chronic obstructive pulmonary disease; $\mathrm{FEV}_{1}$, forced expiratory volume in one second; FVC, forced vital capacity; PRISm, preserved ratio impaired spirometry. Data represent original data without imputed values. Missing values were present for education attainment (1.0\%), systolic blood pressure (2.8\%), triglyceride (1.7\%), and history of diabetes $(7.1 \%)$. *Fisher's exact test.

for using propensity scores. Propensity scores were employed to reduce the number of covariates through summarizing information of variables into a single score, thus avoiding any problem of overfitting the models $[19,20]$. In this study, propensity scores are the predicted probabilities of PRISm and COPD and derived by fitting logistic regression models adjusting for age, sex, education level, smoking status, systolic blood pressure, BMI, triglycerides, chronic comorbid conditions (diabetes and stroke), and APOE phenotypes.

We also studied how PRISm and COPD related to the risk of mortality to gauge the possible effect of competing risk in our associations. The competing risk, such as death before occurrence of incident dementia, are considered as independent event but is neglected in conventional methods for survival analyses, thus the true observation of the event of interest could be hindered in the presence of competing risk and then distort the association we explored [21]. For unadjusted survival analyses intended to portray absolute risks, we used sub-distribution hazard models to account for competing risks to estimate cumulative incidence of dementia and all-cause death [22].
In addition, we conducted stratified analyses in women, men, non-smoking participants, smokers and participants without $A P O E \varepsilon 4$ allele and history of stroke and diabetes. These were selected as possible effect modifiers based on previous literature and biological plausibility [3, 23-27].

\section{RESULTS}

\section{Clinical and lung functional characteristics of participants}

Among 4,765 participants (mean age 68.2 \pm 12.9 years, $54.9 \%$ women), $16.0 \%(n=763)$ had COPD, $6.7 \%(n=319)$ had PRISm, and $77.3 \%(n=3683)$ had normal spirometry. More than twenty percent (23.0\%) of the participants received higher education, and two thirds $(66.1 \%)$ were current or former smokers. The participants had a median BMI of $27.0 \pm 5.1 \mathrm{Kg} / \mathrm{m}^{2}$, systolic blood pressure of $141 \pm 29.0 \mathrm{mmHg}$, and triglyceride level of $1.3 \pm 0.8 \mathrm{mg} / \mathrm{dl}$. While $8.4 \%(n=396)$ had a history of diabetes mellitus, $1.1 \%$ of them experienced stroke before $(n=53) .1,199(27.1 \%)$ participants carried APOE $\varepsilon 4$ allele (Table 1). 
Table 2

Lung function category and risk of dementia

\begin{tabular}{|c|c|c|c|c|c|}
\hline & \multicolumn{5}{|c|}{ All-type dementia } \\
\hline & cases/death/N & FU, years & HR1 $(95 \%$ CI $)$ & HR2 (95\% CI) & HR3 $(95 \%$ CI) \\
\hline Normal & $75 / 179 / 3683$ & $3.3(1.6)$ & 1.0 & 1.0 & 1.0 \\
\hline PRISm & $15 / 25 / 319$ & $3.4(1.6)$ & $2.42(1.38 ; 4.24)$ & $2.70(1.53 ; 4.75)$ & $2.47(1.40 ; 4.35)$ \\
\hline \multirow[t]{3}{*}{ COPD } & $20 / 88 / 763$ & $3.4(1.6)$ & $1.06(0.63 ; 1.77)$ & $1.03(0.61 ; 1.74)$ & $1.08(0.63 ; 1.83)$ \\
\hline & \multicolumn{5}{|c|}{$\mathrm{AD}$} \\
\hline & cases/death/N & FU, years & HR1 $(95 \%$ CI $)$ & $\mathrm{HR} 2(95 \% \mathrm{CI})$ & HR3 (95\% CI) \\
\hline Normal & $65 / 179 / 3673$ & $3.3(1.6)$ & 1.0 & 1.0 & 1.0 \\
\hline PRISm & $9 / 25 / 313$ & $3.4(1.6)$ & $1.70(0.84 ; 3.43)$ & $1.87(0.92 ; 3.81)$ & $1.74(0.86 ; 3.54)$ \\
\hline COPD & $15 / 88 / 758$ & $3.4(1.6)$ & $0.89(0.49 ; 1.60)$ & $0.87(0.48 ; 1.59)$ & $0.89(0.49 ; 1.63)$ \\
\hline
\end{tabular}

$\mathrm{AD}$, Alzheimer's disease; COPD, chronic obstructive pulmonary disease; $\mathrm{CI}$, confidence interval; FU, followup; HR, hazard ratio; PRISm, preserved ratio impaired spirometry; Model 1, Cox regression adjusted for APOE genotype, age, sex, and education level; Model 2, Model 1 plus adjustment smoking status, BMI, systolic blood pressure, triglycerides, and history of comorbidities (stroke and diabetes mellitus); Model 3, Cox regression adjusted for propensity scores*, age, and sex. *Propensity scores was calculated with age, sex, education level, smoking status, BMI, systolic blood pressure, triglyceride, history of comorbidities (stroke and diabetes mellitus) and $A P O E$ genotype; follow-up time started after spirometry at baseline.

\section{Lung function and risk of incident dementia and $A D$}

During a median of 3.3 years of follow-up, 110 participants $(2.3 \%)$ developed incident dementia, of whom 89 (1.9\%) developed AD. Moreover, among all participants, 292 (6.1\%) died due to non-dementia related causes within the follow-up period (Table 2).

First, we evaluated the association between lung function impairment at baseline and risk of incident dementia. As shown in Table 2, higher proportion of participants with PRISm developed dementia compared to participants with normal spirometry, while COPD patients did not. Compared with participants with normal spirometry, participants with PRISm exhibited a higher risk of all-type dementia (Model 2 hazard ratio [HR], 2.70; 95\% confidence interval [CI], 1.53-4.75), while subjects with COPD did not $\left(\mathrm{HR}_{2}, 1.03 ; 95 \% \mathrm{CI}, 0.61-1.74\right)$, after accounting for all covariates. After being adjusted for propensity score, age and sex, results of model 3 were similar to model 2 (Table 2). Hazard ratios of association of PRISm and COPD with all-type dementia were 2.47 (95\% CI, 1.40-4.35) and 1.08 (95\% CI, 0.63-1.83), respectively.

Concurrently, participants with PRISm were also at increased risk of $\mathrm{AD}$, albeit this did not reach statistical significance $\left(\mathrm{HR}_{2}, 1.87\right.$; 95\% CI, 0.92-3.81). COPD was not significantly associated with AD ( $\mathrm{HR}_{2}, 0.87$; 95\% CI, 0.48-1.59) (Table 2).

We also investigated the risk of developing dementia associated with lower lung function by using continuous parameters $\left(\mathrm{FEV}_{1} \%, \mathrm{FVC} \%, \mathrm{FEV}_{1} /\right.$
FVC\%) and their categorized quartiles (Fig. 2). A lower value in $\mathrm{FEV}_{1} \%$ predicted was associated with an elevated risk of all-type dementia $\left(\mathrm{HR}_{2}, 1.12 ; 95 \%\right.$ CI, 1.02-1.23). Relative to participants with the highest FVC\% predicted values (Quartile 4), those with the lowest FVC\% predicted values (Quartile 1) were at increased risk of both all-type dementia (Model 2 hazard ratio $\left[\mathrm{HR}_{2}\right], 2.28 ; 95 \%$ confidence interval $[\mathrm{CI}], 1.31-3.98)$ and $\mathrm{AD}\left(\mathrm{HR}_{2}, 2.13\right.$; 95\% CI, 1.13-4.02), after accounting for demographics and $A P O E$ genotypes. A lower value in $\mathrm{FVC} \%$ predicted was significantly associated with an increased risk of both all-type dementia and $\mathrm{AD}$ in all models. $\mathrm{FEV}_{1} / \mathrm{FVC}$ was not associated with dementia risk in any model (Fig. 2).

Moreover, a competing risk model was used to measure the competing risk of mortality during the follow-up period on the observation of dementia events. Although participants with PRISm suffered from higher cumulative incidence of all-cause mortality than participants with normal spirometry, participants with PRISm still exhibited significantly higher cumulative incidence of all-type dementia $(p=0.018)$, but not of AD $(p>0.05)$ (Supplementary Figure 1).

\section{Stratified analysis}

Methods and figures on the stratified analyses are presented in the Supplementary Material. Regarding the association between COPD or PRISm and the risk of incident dementia, stratified analyses were performed in women, men, smokers, non-smoking 


\section{A}

$\begin{array}{lc}\text { FEV1\% predicted } & \text { HR1 } \\ \text { Per 10\% decline } & 1.11 \\ \text { Quartile 1 } & 1.35 \\ \text { Quartile 2 } & 1.44 \\ \text { Quartile 3 } & 0.97 \\ \text { FVC\% predicted } & \\ \text { Per 10\% decline } & 1.20 \\ \text { Quartile 1 } & 2.07 \\ \text { Quartile 2 } & 1.52 \\ \text { Quartile 3 } & 1.05 \\ \text { FEV1/FVC ratio } & \\ \text { Per 10\% decline } & 0.88 \\ \text { Quartile 1 } & 0.65 \\ \text { Quartile 2 } & 0.70 \\ \text { Quartile 3 } & 0.79\end{array}$

\section{B}

$\begin{array}{lc}\text { FEV1\% predicted } & \text { HR } 1 \\ \text { Per 10\% decline } & 1.07 \\ \text { Quartile 1 } & 1.14 \\ \text { Quartile 2 } & 1.58 \\ \text { Quartile 3 } & 0.92 \\ \text { FVC\% predicted } & \\ \text { Per 10\% decline } & 1.17 \\ \text { Quartile 1 } & 1.93 \\ \text { Quartile 2 } & 1.68 \\ \text { Quartile 3 } & 1.22 \\ \text { FEV1/FVC ratio } & \\ \text { Per 10\% decline } & 0.81 \\ \text { Quartile 1 } & 0.61 \\ \text { Quartile 2 } & 0.62 \\ \text { Quartile 3 } & 0.84\end{array}$

\section{All-type dementia}


Alzheimer's Disease



$\mathrm{HR}_{2}$
1.08
1.17
1.63
0.91

1.20
2.13
1.67
1.28

0.78
0.55
0.57
0.79



Fig. 2. Respiratory indexes ( $\mathrm{FEV}_{1} \%$ predicted, $\mathrm{FVC} \%$ predicted and $\mathrm{FEV}_{1} / \mathrm{FVC}$ ratio) and risk of dementia (A) and Alzheimer's disease (B). $\mathrm{AD}$, Alzheimer's disease; A, All-type dementia; B, Alzheimer's disease; CI, confidence interval; HR, hazard ratio; FEV 1 , Forced Expiratory volume in one second; FVC, forced vital capacity; HR1, HR from Cox Proportional-Hazard regression analysis adjusted for APOE genotype, age, sex, and education level; HR2, HR1 with additional adjustment for current or ever smoking, BMI, systolic blood pressure, triglyceride, and history of comorbidities (stroke and diabetes mellitus). Participants in the highest percentile (Quartile 4) of spirometry indexes were regarded as reference group (hidden). * follow-up time start after spirometry at baseline.

participants, participants without history of stroke and diabetes, and $A P O E \varepsilon 4$ non-carriers. Significant associations were found between PRISm and alltype dementia in men (adjusted $\mathrm{HR}=5.29,95 \% \mathrm{CI}$, 2.40-11.65), but not in women (adjusted $\mathrm{HR}=1.65$, 95\% CI, 0.71-3.87); current or former smokers (adjusted HR $=3.36$, 95\% CI, 1.71-6.60), but not in never-smoking participants (adjusted HR $=1.95$, 95\% CI, 0.68-5.57); participants without a history of stroke (adjusted HR $=2.58,95 \% \mathrm{CI}, 1.45-4.59$ ) and diabetes (adjusted $\mathrm{HR}=2.56,95 \% \mathrm{CI}, 1.38-4.78$ ); and participants without $A P O E \varepsilon 4$ allele $(\mathrm{HR}=1.56$, 95\% CI, 0.71-3.45). Significant association between PRISm and AD risk were only observed among men (Supplementary Figure 2).

We have tested the effect of interaction of lung function and sex, and interaction of lung function and smoking status in cox models, respectively, which 
tests for multiplicative interaction. These tests of interaction did not reach statistical significance (data not shown).

In addition, Supplementary Figure 3 shows the association between continuous spirometry parameters with the risk of newly diagnosed dementia (Supplementary Figure 3A) or newly diagnosed AD (Supplementary Figure 3B), stratified by sex, smoking status and absence of stroke, diabetes, and $A P O E \& 4$ non-carriers. A lower $\mathrm{FEV}_{1} \%$ predicted was associated with a greater risk of all-type dementia only among women, never-smoking participants, and those without prior stroke, but not among men, current or former smoking participants, and participants without prior diabetes and $A P O E \varepsilon 4$ noncarriers. A lower $\mathrm{FVC} \%$ predicted was associated with an increased risk of all-type dementia among all subgroups except $A P O E \varepsilon 4$ non-carriers. Statistical significance was not found between decreased $\mathrm{FEV}_{1} / \mathrm{FVC}$ and risk of all-type dementia. Regarding elevated risk of $\mathrm{AD}$, reduced $\mathrm{FVC} \%$ predicted and $\mathrm{FEV}_{1} / \mathrm{FVC}$ elevated were associated with $\mathrm{AD}$ among women, nonsmokers and those without prior stroke, while $\mathrm{FEV}_{1} \%$ predicted did not show an increased risk of $\mathrm{AD}$ among those without prior stroke.

\section{DISCUSSION}

In this population-based cohort study, individuals with PRISm were at increased risk of all-type dementia, while those with COPD were not. Especially, predicted FVC\% was strongly associated with a higher risk of dementia among the whole study population.

The main finding of this study is that PRISm was associated with an increased risk of dementia. Comorbidities, such as diabetes and stroke, are more common among participants of this restrictive lungfunction pattern [28], and may confound the link with impaired cognition and the increased risk for dementia. However, while we found a higher prevalence of prior stroke in participants with PRISm, the association between PRISm and dementia persisted after adjusting for these comorbidities. There are several possible mechanisms linking PRISm with dementia. Firstly, ambient pollution and inhalational exposures are associated with higher risk of PRISm [29], which could also contribute to the development of dementia $[30,31]$. For example, fine particulate matter in air could not only lead to impaired lung function through disturbing alveolarization process and altering lung elastance at an earlier life stage [32], but also be linked to higher dementia risk via accumulation of $A \beta_{42}$ and alteration on neuroinflammation and brain immune response, as exposure to certain level of air pollution could upregulate expression of mRNA COX2 and IL- $1 \beta$ in olfactory bulb, disrupt tight junctions in frontal blood-brain barrier and activate nuclear $\mathrm{NF} \kappa \mathrm{B}$ in brain endothelial cells [31, 33].

Secondly, some studies reported that FVC decline in subjects with PRISm was accompanied with systemic inflammation [34-36]. Systemic inflammation in turn may be linked with cognitive impairment and/ or occurrence of dementia [37]. Serum inflammatory cytokines, like (IL)-18, IL-1 receptor antagonist and IL-6, have been linked with AD [38], and high levels of serum IL-6 were associated with a greater risk of non-AD dementia as well [39]. Unfortunately, we did not have inflammatory markers available in this population to test this hypothesis.

Thirdly, reduced lung function could limit peak oxygen uptake and oxygen saturation, resulting in potential hypoxia [6, 40, 41]. In turn, hypoxia has been reported to induce cognitive deficiency and dementia in both human and animal studies [42, 43]. Mice with hypoxia exhibited tau hyperphosphorylation, $A \beta$ upregulation, and dysfunction of neurotransmitter system [43].

In stratified analyses, we found that the association between PRISm and dementia was present in men, current and past smokers, and participants without history of stroke and diabetes.

Though speculative, sex differences can potentially be explained by unmeasured confounding by sex hormones [44, 45]. Indeed, estrogen has protective effects on systemic and cerebrovascular atherosclerosis, which in turn impact both lung function and dementia risk [24, 44]. In this population-based study, we could not corroborate this speculation and future research is therefore needed to explore these hypotheses further.

The effect modification by smoking status indicates that the effect of poor lung function on risk of dementia is further aggravated in presence of smoking. This may be related to direct toxic effects of smoking in the brain, for instance increased levels of oxidants and free radical species, which promotes formation of senile plaque and neurofibrillary tangles. In turn, these pathological processes may interact with cerebral hypoxia and hypoperfusion due to poor lung function $[46,47]$.

With respect to stroke, $A P O E \varepsilon 4$ carriership and diabetes, we only had sufficient power to show the 
largest stratum and found that associations among persons without stroke, $A P O E \varepsilon 4$ non-carriers, and non-diabetics remained largely similar to the overall population.

Among continuous lung function parameters, $\mathrm{FVC} \%$ predicted, but not $\mathrm{FEV}_{1} / \mathrm{FVC}$ ratio or $\mathrm{FEV}_{1} \%$ predicted, was significantly associated with both alltype dementia and AD risk. Previous studies have varyingly reported on $\mathrm{FEV}_{1}, \mathrm{FEV}_{1} / \mathrm{FVR}$ ratio, or FVC\% predicted to be associated with dementia. Heterogeneity across study population, including differences in age-range, sampling strategy and comorbid conditions may explain differences in the strength of associations of the various parameters with dementia.

We did not demonstrate an association between COPD and the risk of dementia, in contrast to the prior study [14]. Previously, we found participants with PRISm and COPD to suffer from increased all-cause and cardiovascular mortality [7], and similarly the present competing risk model suggested the highest figure of all-cause mortality in COPD group. Therefore, mortality may hinder the occurrence of incident dementia during the follow-up period.

\section{Strengths and limitations}

An important strength of this study is the relatively large number of elderly participants included for assessment of the lung function through standardized protocols and dementia data based on continuous follow-up. Competing risks is a limitation when using traditional cox proportion-hazard regression analyses. However, we used competing risk model to calculate cumulative risk of dementia to correct effect of variable of interest. The small number of incident dementia cases limited our study power, but we applied propensity scores to avoid potential overfitting problem with adjustment for extensive covariates.

\section{CONCLUSIONS}

As a conclusion, among this community-dwelling population, participants with PRISm or participants with a low $\mathrm{FVC} \%$ predicted lung function were at increased risk of dementia, compared to those with normal spirometry or a higher FVC\% predicted, respectively. Further research is needed to elucidate whether this association is causal and how PRISm might contribute to dementia pathogenesis. Therefore, it is necessary to recognize PRISm and evaluate status of FVC\% predicted when conducting spirometry tests in clinical settings.

\section{ACKNOWLEDGMENTS}

The authors thank the study participants, the staff from the Rotterdam Study and the participating general practitioners. This research was funded by the 'Funds for Scientific Research Flanders (Fonds voor Wetenschappelijk Onderzoek Vlaanderen)', grant number 3G037618. The Rotterdam Study is supported by the Erasmus MC and Erasmus University Rotterdam; the Netherlands Organisation for Scientific Research (NWO); the Netherlands Organisation for Health Research and Development (ZonMW); the Research Institute for Diseases in the Elderly (RIDE); the Netherlands Genomics Initiative; the Ministry of Education, Culture and Science; the Ministry of Health, Welfare and Sports; the European Commission (DG XII); and the Municipality of Rotterdam. Further funding for this study was obtained through ZonMW grant number 733051107 as part of the "From air pollution to brain pollution - novel biomarkers to unravel the link of air pollution and Alzheimer's disease" (ADAIR) consortium under the umbrella of the Joint Programme - Neurodegenerative Diseases Research (JPND). The funding sources had no involvement in the collection, analysis, writing, interpretation, or in the decision to submit the paper for publication.

Authors' disclosures available online (https:// www.j-alz.com/manuscript-disclosures/21-0162r1).

\section{SUPPLEMENTARY MATERIAL}

The supplementary material is available in the electronic version of this article: https://dx.doi.org/ 10.3233/JAD-210162.

\section{DATA AVAILABILITY}

Data may be shared on request through contacting with Dr. Arfan.

\section{REFERENCES}

[1] Ezzati A, Zammit AR, Katz MJ, Derby CA, Zimmerman ME, Lipton RB (2019) Health-related quality of life, cognitive performance, and incident dementia in a community-based elderly cohort. Alzheimer Dis Assoc Disord 33, 240-245.

[2] Stephan BCM, Birdi R, Tang EYH, Cosco TD, Donini LM, Licher S, Ikram MA, Siervo M, Robinson L (2018) Secular 
trends in dementia prevalence and incidence worldwide: A systematic review. J Alzheimers Dis 66, 653-680.

[3] Baumgart M, Snyder HM, Carrillo MC, Fazio S, Kim H, Johns H (2015) Summary of the evidence on modifiable risk factors for cognitive decline and dementia: A populationbased perspective. Alzheimers Dement 11, 718-726.

[4] Dodd JW (2015) Lung disease as a determinant of cognitive decline and dementia. Alzheimers Res Ther 7, 32.

[5] Gramiccioni C, Carpagnano GE, Spanevello A, Turchiarelli V, Cagnazzo MG, Foschino Barbaro MP (2010) Airways oxidative stress, lung function and cognitive impairment in aging. Monaldi Arch Chest Dis 73, 5-11.

[6] Areza-Fegyveres R, Kairalla RA, Carvalho CRR, Nitrini R (2010) Cognition and chronic hypoxia in pulmonary diseases. Dement Neuropsychol 4, 14-22.

[7] Wijnant SRA, De Roos E, Kavousi M, Stricker BH, Terzikhan N, Lahousse L, Brusselle GG (2020) Trajectory and mortality of preserved ratio impaired spirometry: The Rotterdam Study. Eur Respir J 55, 1901217.

[8] Wan ES, Fortis S, Regan EA, Hokanson J, Han MK, Casaburi R, Make BJ, Crapo JD, DeMeo DL, Silverman EK, COPDGene Investigators (2018) Longitudinal phenotypes and mortality in preserved ratio impaired spirometry in the COPDGene study. Am J Respir Crit Care Med 198, 1397-1405.

[9] Vogelmeier CF, Criner GJ, Martinez FJ, Anzueto A, Barnes PJ, Bourbeau J, Celli BR, Chen R, Decramer M, Fabbri LM, Frith P, Halpin DM, Lopez Varela MV, Nishimura M, Roche N, Rodriguez-Roisin R, Sin DD, Singh D, Stockley R, Vestbo J, Wedzicha JA, Agusti A (2017) Global Strategy for the Diagnosis, Management, and Prevention of Chronic Obstructive Lung Disease 2017 Report: GOLD Executive Summary. Eur Respir J 49, 1700214.

[10] Guerra S, Sherrill DL, Venker C, Ceccato CM, Halonen M, Martinez FD (2010) Morbidity and mortality associated with the restrictive spirometric pattern: A longitudinal study. Thorax 65, 499-504.

[11] Ikram MA, Brusselle G, Ghanbari M, Goedegebure A, Ikram MK, Kavousi M, Kieboom BCT, Klaver CCW, de Knegt RJ, Luik AI, Nijsten TEC, Peeters RP, van Rooij FJA, Stricker BH, Uitterlinden AG, Vernooij MW, Voortman T (2020) Objectives, design and main findings until 2020 from the Rotterdam Study. Eur J Epidemiol 35, 483-517.

[12] Celli BR, MacNee W, Force AET (2004) Standards for the diagnosis and treatment of patients with COPD: A summary of the ATS/ERS position paper. Eur Respir $J$ 23, 932-946.

[13] Graham BL, Brusasco V, Burgos F, Cooper BG, Jensen R, Kendrick A, MacIntyre NR, Thompson BR, Wanger J (2017) 2017 ERS/ATS standards for single-breath carbon monoxide uptake in the lung. Eur Respir J 49, 1600016.

[14] Lutsey PL, Chen N, Mirabelli MC, Lakshminarayan K, Knopman DS, Vossel KA, Gottesman RF, Mosley TH, Alonso A (2019) Impaired lung function, lung disease, and risk of incident dementia. Am J Respir Crit Care Med 199, 1385-1396.

[15] de Bruijn RF, Bos MJ, Portegies ML, Hofman A, Franco OH, Koudstaal PJ, Ikram MA (2015) The potential for prevention of dementia across two decades: The prospective, population-based Rotterdam Study. BMC Med 13, 132.

[16] Licher S, Ahmad S, Karamujic-Comic H, Voortman T, Leening MJG, Ikram MA, Ikram MK (2019) Genetic predisposition, modifiable-risk-factor profile and long-term dementia risk in the general population. Nat Med 25, 13641369.
[17] Pathan SS, Gottesman RF, Mosley TH, Knopman DS, Sharrett AR, Alonso A (2011) Association of lung function with cognitive decline and dementia: The Atherosclerosis Risk in Communities (ARIC) Study. Eur J Neurol 18, 888-898.

[18] Zhang Z (2016) Multiple imputation with multivariate imputation by chained equation (MICE) package. Ann Transl Med 4, 30

[19] Austin PC (2011) An introduction to propensity score methods for reducing the effects of confounding in observational studies. Multivariate Behav Res 46, 399-424.

[20] Little RJ, Rubin DB (2000) Causal effects in clinical and epidemiological studies via potential outcomes: Concepts and analytical approaches. Annu Rev Public Health 21, 121-145.

[21] Noordzij M, Leffondre K, van Stralen KJ, Zoccali C, Dekker FW, Jager KJ (2013) When do we need competing risks methods for survival analysis in nephrology? Nephrol Dial Transplant 28, 2670-2677.

[22] Scrucca L, Santucci A, Aversa F (2010) Regression modeling of competing risk using R: An in depth guide for clinicians. Bone Marrow Transplant 45, 1388-1395.

[23] Hachinski V, Einhaupl K, Ganten D, Alladi S, Brayne C, Stephan BCM, Sweeney MD, Zlokovic B, Iturria-Medina Y, Iadecola C, Nishimura N, Schaffer CB, Whitehead SN, Black SE, Ostergaard L, Wardlaw J, Greenberg S, Friberg L, Norrving B, Rowe B, Joanette Y, Hacke W, Kuller L, Dichgans M, Endres M, Khachaturian ZS (2019) Preventing dementia by preventing stroke: The Berlin Manifesto. Alzheimers Dement 15, 961-984.

[24] Rocca WA, Mielke MM, Vemuri P, Miller VM (2014) Sex and gender differences in the causes of dementia: A narrative review. Maturitas 79, 196-201.

[25] Xue M, Xu W, Ou YN, Cao XP, Tan MS, Tan L, Yu JT (2019) Diabetes mellitus and risks of cognitive impairment and dementia: A systematic review and meta-analysis of 144 prospective studies. Ageing Res Rev 55, 100944.

[26] Biessels GJ, Despa F (2018) Cognitive decline and dementia in diabetes mellitus: Mechanisms and clinical implications. Nat Rev Endocrinol 14, 591-604.

[27] Saunders AM, Strittmatter WJ, Schmechel D, GeorgeHyslop PH, Pericak-Vance MA, Joo SH, Rosi BL, Gusella JF, Crapper-MacLachlan DR, Alberts MJ, et al. (1993) Association of apolipoprotein E allele epsilon 4 with lateonset familial and sporadic Alzheimer's disease. Neurology 43, 1467-1472.

[28] Scarlata S, Pedone C, Fimognari FL, Bellia V, Forastiere F, Incalzi RA (2008) Restrictive pulmonary dysfunction at spirometry and mortality in the elderly. Respir Med 102, 1349-1354.

[29] Wijnant SRA, Lahousse L, Brusselle GG (2020) The global significance of PRISm: How data from low- and middleincome countries link physiology to inflammation. Eur Respir J 55, 2000354.

[30] Zhong G, Wang Y, Zhang Y, Guo JJ, Zhao Y (2015) Smoking is associated with an increased risk of dementia: A metaanalysis of prospective cohort studies with investigation of potential effect modifiers. PLoS One 10, e0118333.

[31] Chen H, Kwong JC, Copes R, Hystad P, van Donkelaar A, Tu K, Brook JR, Goldberg MS, Martin RV, Murray BJ, Wilton AS, Kopp A, Burnett RT (2017) Exposure to ambient air pollution and the incidence of dementia: A population-based cohort study. Environ Int 108, 271-277.

[32] de Barros Mendes Lopes T, Groth EE, Veras M, Furuya TK, de Souza Xavier Costa N, Ribeiro Junior G, Lopes FD, de Almeida FM, Cardoso WV, Saldiva PHN, Chammas R, 
Mauad T (2018) Pre- and postnatal exposure of mice to concentrated urban PM2.5 decreases the number of alveoli and leads to altered lung function at an early stage of life. Environ Pollut 241, 511-520.

[33] Calderon-Garciduenas L, Solt AC, Henriquez-Roldan C, Torres-Jardon R, Nuse B, Herritt L, Villarreal-Calderon R, Osnaya N, Stone I, Garcia R, Brooks DM, GonzalezMaciel A, Reynoso-Robles R, Delgado-Chavez R, Reed W (2008) Long-term air pollution exposure is associated with neuroinflammation, an altered innate immune response, disruption of the blood-brain barrier, ultrafine particulate deposition, and accumulation of amyloid beta- 42 and alphasynuclein in children and young adults. Toxicol Pathol 36, 289-310.

[34] Wannamethee SG, Shaper AG, Rumley A, Sattar N, Whincup PH, Thomas MC, Lowe GD (2010) Lung function and risk of type 2 diabetes and fatal and nonfatal major coronary heart disease events: Possible associations with inflammation. Diabetes Care 33, 1990-1996.

[35] Thyagarajan B, Jacobs DR, Apostol GG, Smith LJ, Lewis CE, Williams OD (2006) Plasma fibrinogen and lung function: The CARDIA Study. Int J Epidemiol 35, 10011008.

[36] Kalhan R, Tran BT, Colangelo LA, Rosenberg SR, Liu K, Thyagarajan B, Jacobs DR, Jr., Smith LJ (2010) Systemic inflammation in young adults is associated with abnormal lung function in middle age. PLoS One $\mathbf{5}$, e11431.

[37] Cunningham C (2011) Systemic inflammation and delirium: Important co-factors in the progression of dementia. Biochem Soc Trans 39, 945-953.

[38] Tsui A, Davis D (2018) Systemic inflammation and causal risk for Alzheimer's dementia: Possibilities and limitations of a Mendelian randomization approach. Aging Med (Milton) 1, 249-253.
[39] Sundelof J, Kilander L, Helmersson J, Larsson A, Ronnemaa E, Degerman-Gunnarsson M, Basun H, Lannfelt L, Basu S (2009) Systemic inflammation and the risk of Alzheimer's disease and dementia: A prospective population-based study. J Alzheimers Dis 18, 79-87.

[40] Hassel E, Stensvold D, Halvorsen T, Wisløff U, Langhammer A, Steinshamn S (2015) Association between pulmonary function and peak oxygen uptake in elderly: The Generation 100 study. Respir Res 16, 156.

[41] Vold ML, Aaseb $\varnothing$ U, Melbye H (2014) Low FEV1, smoking history, and obesity are factors associated with oxygen saturation decrease in an adult population cohort. Int J Chron Obstruct Pulmon Dis 9, 1225-1233.

[42] Yaffe K, Laffan AM, Harrison SL, Redline S, Spira AP, Ensrud KE, Ancoli-Israel S, Stone KL (2011) Sleepdisordered breathing, hypoxia, and risk of mild cognitive impairment and dementia in older women. JAMA 306, 613-619.

[43] Kaushal A, Wani WY, Bal A, Gill KD, Kaur J (2019) Okadaic acid and hypoxia induced dementia model of Alzheimer's type in rats. Neurotox Res 35, 621-634.

[44] De Silva TM, Faraci FM (2012) Effects of angiotensin II on the cerebral circulation: Role of oxidative stress. Front Physiol 3, 484.

[45] Almeida OP, Barclay L (2001) Sex hormones and their impact on dementia and depression: A clinical perspective. Expert Opin Pharmacother 2, 527-535.

[46] Durazzo TC, Mattsson N, Weiner MW, Alzheimer's Disease Neuroimaging Initiative (2014) Smoking and increased Alzheimer's disease risk: A review of potential mechanisms. Alzheimers Dement 10, S122-145.

[47] Burke A, Fitzgerald GA (2003) Oxidative stress and smoking-induced vascular injury. Prog Cardiovasc Dis 46, 79-90. 